\title{
Cholestyramine in the peritoneal cavity of the rat
}

\author{
E. M. WALKER \\ F.R.C.S.
}

The General Hospital, Nottingham

\begin{abstract}
Summary
The effects of cholestyramine in the peritoneal cavity of the rat are described. Cholestyramine causes mild peritonitis with adhesion formation between the liver and the omentum. In the management of biliary peritonitis, a lavage solution containing a suspension of cholestyramine would appear to be contra-indicated by these experimental studies.
\end{abstract}

\section{Introduction}

Cholestyramine, a basic anion exchange resin which has an affinity for bile salts, has been used to increase the excretion of bile salts from the alimentary tract.

In rats, bile salts injected into the peritoneal cavity produce peritonitis similar to the peritonitis caused by the injection of whole bile, whereas the injection of cholesterol or phospholipid causes little peritoneal reaction (Walker and Ellis, 1978).

The morbidity and mortality of biliary peritonitis has decreased with the introduction of early surgical drainage and peritoneal lavage. McWilliams (1911) reported $51 \%$ mortality in a review of 108 cases of biliary perforation. Various authors since then have given mortality figures for biliary peritonitis of $70 \%$ (MacDonald, 1966), 50\% (Ellis and Cronin, 1960), 40\% (Ellis and Adair 1974), 39\% (Essenhigh, 1968), $29 \%$ (McEarchern and Sullivan, 1963), and 25\% (Leborgne et al., 1972). Lilly, Weintraub and Altman (1974) reviewed 53 infants with spontaneous perforation of the extrahepatic bile ducts with a $20 \%$ mortality. In these patients the peritonitis was usually sterile, indicating that the constituents of bile rather than bacterial contamination were responsible for peritonitis. In adults the role of infection in biliary peritonitis remains unclear.

Since cholestyramine has an affinity for bile salts, its incorporation in a peritoneal lavage solution might enhance the removal of bile salts from the peritoneal cavity.

An experimental study of the effects of cholestyramine in the peritoneal cavity of the rat is now presented.
Method

Female Sprague Dawley rats weighing approximately $200 \mathrm{~g}$ were used for these experiments.

Questran, the chloride salt of cholestyramine was supplied by Mead Johnson Laboratories.

A suspension of $20 \mathrm{mg} / \mathrm{ml}$ cholestyramine was made in a 0.02 molar phosphate buffer $\mathrm{pH} \mathrm{6.8.} \mathrm{This}$ quantity of cholestyramine would be expected to bind $20 \mathrm{mg} / \mathrm{ml}$ bile salt in vitro. One $\mathrm{ml}$ of the suspension was injected into the peritoneal cavity of each of 6 rats, and $2 \mathrm{ml}$ into each of a further 6 rats. The animals were killed at intervals up to 6 months and specimens of the peritoneum and omentum examined in histological sections stained with haematoxolin and eosin.

\section{Results}

All animals survived until they were killed. The changes described were more severe in the animals receiving $2 \mathrm{ml}$ of the suspension than in the animals receiving one $\mathrm{ml}$, but the nature of the changes was similar and the 2 groups will be considered together.

Twenty-four hours after the injection of cholestyramine, clumps of yellow material were found within the omentum. Histological section showed this to be cholestyramine. The peritoneum showed an acute inflammatory reaction with particles of cholestyramine within the peritoneum (Fig. 1). Five days after the injection of cholestyramine the omentum, heavily laden with cholestyramine, was adherent to the liver(Fig. 2). The particles of cholestyramine in the peritoneum were surrounded by macrophages. By 30 days there was a florid foreign body giant cell reaction in both the peritoneum and the omentum. After 6 months the peritoneum appeared macroscopically normal, but there were still many cholestyramine particles in it in the histological sections. The omentum was firmly adherent to the liver, and contained many particles of cholestyramine.

\section{Discussion}

The rat provides a suitable animal model in which 


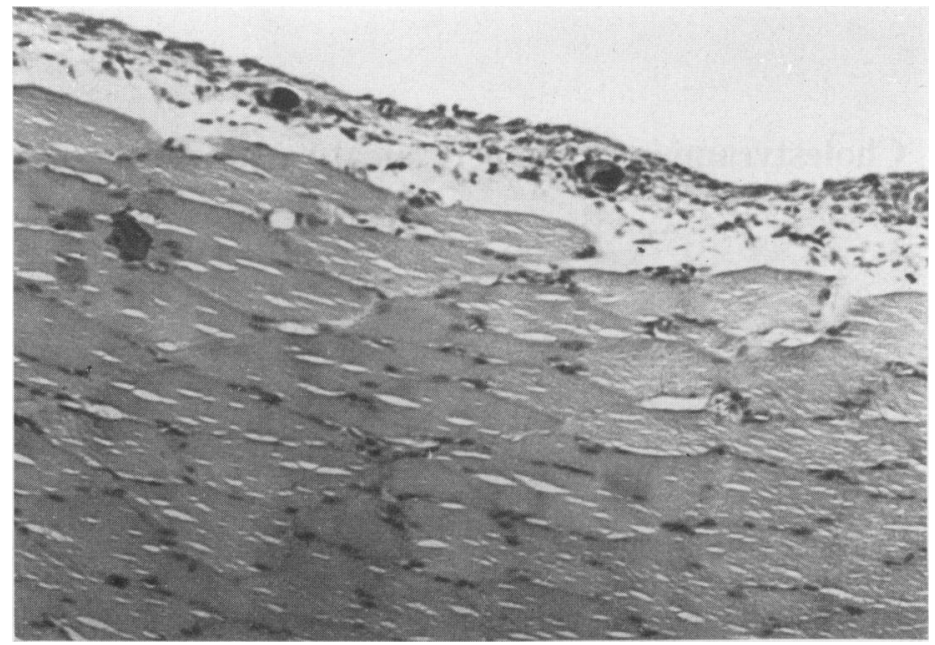

FIG. 1. Section of peritoneum $24 \mathrm{hr}$ after cholestyramine injection. The peritoneum contains cholestyramine particles surrounded by an acute inflammatory reaction $(\mathrm{HE}, \times 80)$.

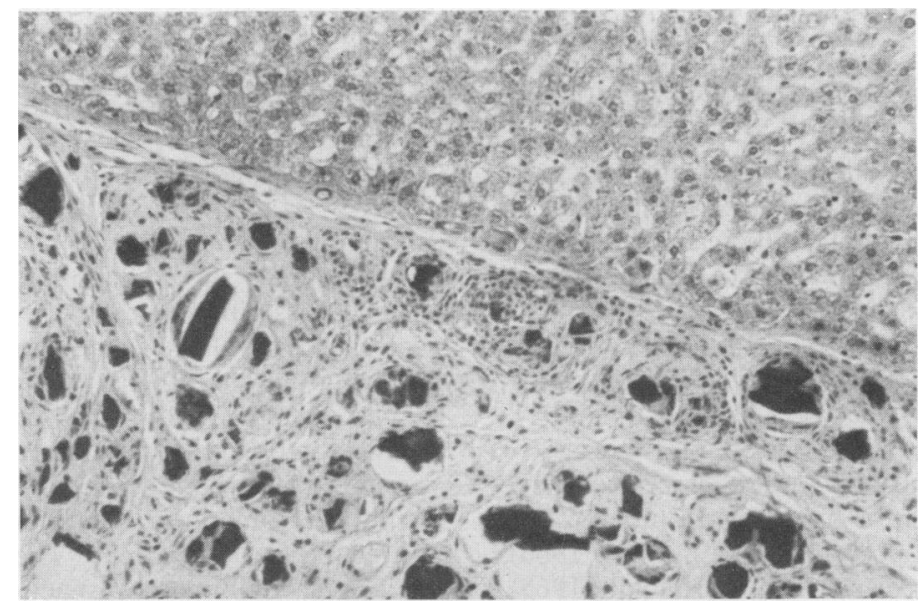

FIG. 2. Section of omentum and liver firmly adherent 5 days after the injection of cholestyramine $(\mathrm{HE}, \times 80)$.

to study the effects of intraperitoneal irritants. However, it must be appreciated that the rat peritoneum may handle chemical irritants in a different manner from the human peritoneum.

The role of bile salts in the production of biliary peritonitis has been described previously (Walker and Ellis, 1978). The use of cholestyramine within the peritoneal cavity has not been reported. The use of cholestyramine within the peritoneal cavity is contraindicated because of the peritonitis caused and the adhesions between the omentum and the liver.
Adhesions were not seen between other organs. The adhesions between the cholestyramine-laden omen- $\frac{7}{2}$ tum and the liver are difficult to explain since the bile salts in the liver are either within cells or ducts and $\sigma$ have no direct contact with the liver surface.

\section{Acknowledgment}

I wish to thank the Special Trustees of the Nottingham $\mathbb{D}$ University Hospitals for the grant which made this work $\stackrel{\mathscr{C}}{+}$ possible. 


\section{References}

EluIs, H. \& AdaIR, H.M. (1974) Bile peritonitis - a report of fifteen patients. Postgraduate Medical Journal, 50, 713.

Ellis, H. \& Cronin, K. (1960) Bile peritonitis. British Journal of Surgery, 48, 166.

EsSenhigh, D.M. (1968). Perforation of the gall bladder. British Journal of Surgery, 55, 175.

Leborgne, J., Le Neel, J.C., Visset, J. \& Mousseau, M. (1972). Les péritonites biliaires. Annales de Chirurgie, 26, 153.

Lilly, J.R., Weintraub, W.H. \& Altman, R.P. (1974). Spontaneous perforation of the extrahepatic bile ducts and bile peritonitis in infancy. Surgery, 75, 664.

MacDonald, J.A. (1966) Perforation of the gall bladder associated with acute cholecystitis. Annals of Surgery, 164, 849.

McEarchern, C.G. \& Sullivan, R.E. (1963). Perforation of the gall bladder. Analysis of 21 cases. Archives of Surgery, 87, 489.

McWilliams, C.A. (1911). Acute spontaneous perforation of the biliary system into the free peritoneal cavity, Annals of Surgery, 55, 235.

WALKeR, E.M. \& Ellis, H. (1978). Relationship of the constituents of bile to biliary peritonitis in the rat. Gut, 19, 827. 